\title{
TRINTA ANOS DE AUTONOMIA UNIVERSITÁRIA: RESULTADOS DIVERSOS, EFEITOS CONTRADITÓRIOS
}

\author{
Nina Beatriz Stocco Ranieri ${ }^{1}$ (D)
}

\begin{abstract}
RESUMO: Analisada em perspectiva, a evolução da autonomia universitária no Brasil nas últimas três décadas apresenta diferentes resultados para o sistema público e o privado - o primeiro com liberdade acadêmica e o segundo com autonomia administrativa e de gestáo financeira e patrimonial, exclusivamente. A exceção são as universidades estaduais paulistas, onde os resultados apresentam equilíbrio entre as diversas vertentes da autonomia. As exigências das primeiras décadas do século XXI impóem revisão do exercício da autonomia pelas instituiçôes em razão da internacionalização do ensino superior, das exigências de aprimoramento da gestão e de accountability no setor público.
\end{abstract}

Palavras-chave: Autonomia universitária. Constituição Federal Brasileira de 1988. Evolução. Instituiçóes públicas e privadas.

\section{THIRTY YEARS OF UNIVERSITY AUTONOMY: DIFFERENT RESULTS, CONTRADICTORY EFFECTS}

ABSTRACT: The evolution of university autonomy in Brazil in the last three decades presents different results for both public and private systems. While the public system enjoys academic freedom and no administrative or financial autonomy, private system has financial and administrative autonomy but no academic freedom. The exception is the public state universities of São Paulo, where results show a balance between both aspects of the autonomy. The demands of the $21^{\text {st }}$ century's first decades, however, have imposed a review of the exercise of autonomy by all institutions, due to the internationalization of higher education, the requirements for improving management in general and promoting accountability in the public sector.

Keywords: University autonomy. Brazilian Federal Constitution of 1988. Evolution. Public and private institutions.

${ }^{1}$ Universidade de São Paulo, Faculdade de Direito - São Paulo (SP), Brasil. E-mail: nranieri@usp.br DOI: 10.1590/ES0101-73302018205173 


\title{
TRENTE ANNÉES D'AUTONOMIE UNIVERSITAIRE : RÉSULTATS DIVERS, EFFETS CONTRADICTOIRES
}

\begin{abstract}
RESUMÉ : Analysée en perspective, l'évolution de l'autonomie universitaire au Brésil au cours des trois dernières décennies a produit des résultats différents dans le système public et le système privé, bien que les deux ont une autonomie à mi-chemin dans des zones distinctes. L'exception sont les universités de l'État de São Paulo, où les résultats montrent un équilibre entre les divers aspects d'autonomie. Les exigences des premières décennies du 21 ème siècle imposent un re-examen de l'autonomie par les institutions en raison de l'internationalisation de l'enseignement supérieur, des exigences d'amélioration de la gestion et de la responsabilité dans le secteur public.
\end{abstract}

Mots-clés : Autonomie universitaire. Constitution Brésiliènne de 1988. Evolution. Institutions publiques et privées.

\section{Introdução}

A utonomia universitária é um conceito dinâmico. Varia no tempo e no espaço, conforme circunstancias históricas, políticas e jurídicas. Altamente contextual, a autonomia das universidades medievais de Paris ou Bolonha não é a mesma da Universidade de Berlim no século XIX ou das universidades brasileiras durante a Assembleia Constituinte de 1987, por exemplo. A autonomia universitária estará sempre em movimento e nunca será ideal. Postulado fundado na significação social do trabalho acadêmico e em sua natureza autônoma, compreende prerrogativas de autogoverno atribuídas às universidades nas áreas didático-científica, administrativa e de gestão financeira e patrimonial para que melhor desempenhem atividades de ensino, pesquisa e extensão de serviços à comunidade.

No Brasil, a Constituição Federal (CF) de 1988 consagrou a proteção da autonomia universitária como bem jurídico, protegido pela norma do art. 207:

As universidades gozam de autonomia didático-científica, administrativa e de gestão financeira e patrimonial, e obedecerão ao princípio de indissociabilidade entre ensino, pesquisa e extensão.

$\$ 1^{\circ}$ É facultado às universidades admitir professores, técnicos e cientistas estrangeiros, na forma da lei.

$2^{\circ} \mathrm{O}$ disposto neste artigo aplica-se às instituiçóes de pesquisa científica e tecnológica (BRASIL, 1988b). 
No período de trinta anos, desde a promulgação da Constituição, produziram-se, no país, três principais modelos de autonomia universitária: o das universidades privadas, o das universidades federais e o das universidades estaduais paulistas. Esse último, de longe, é o mais efetivo, dada a estrutura orçamentária e financeira que o assegura e os resultados acadêmicos e científicos apresentados.

Assegurado pelo Decreto estadual no 29.598/89 (BRASIL, 1989), o regime de autonomia das universidades estaduais paulistas (Universidade de São Paulo - USP, Universidade Estadual de Campinas — UNICAMP e Universidade Estadual Paulista "Júlio de Mesquita Filho" — UNESP) é único no país. Seu mecanismo de financiamento prevê o repasse de verbas públicas $(9,57 \%$ do Imposto sobre Operaçóes relativas à Circulação de Mercadorias e sobre Prestaçóes de Serviços de Transporte Interestadual e Intermunicipal e de Comunicação — ICMS) às instituições, em duodécimos mensais, sendo verbas administradas autonomamente pelas instituiçóes. $\mathrm{O}$ montante de recursos que o sustenta foi sucessivamente ampliado por leis orçamentárias anuais. Seus artífices e atores — as universidades, as autoridades do Executivo, do Legislativo (incluído o Tribunal de Contas) e do Judiciário, e o Ministério Público — , tiveram e ainda terão papel crucial em seu aprimoramento jurídico e institucional.

Os demais modelos constituíram-se palmilhando caminhos diferentes. Para as 63 universidades federais (BRASIL, 2017), financiadas com recursos do Tesouro Nacional e algumas fontes alternativas (convênios, contratos, financiamento de pesquisas), o art. 207 não se mostrou efetivo. Problemas diversos de natureza administrativa e financeira (regime de caixa único, contingenciamento de despesas), o peso da burocracia estatal, além das restriçóes do regime de direito público são fatores limitantes de sua autonomia. Comparativamente, as universidades privadas desfrutam de maior autonomia administrativa e financeira em virtude do regime jurídico privado, com vantagens para as instituiçóes que optaram pelo regime mercantil.

Em qualquer dos regimes de autonomia, o exercício de suas prerrogativas submete-se ao peso e às dimensóes da intervenção e do controle estatal na educação superior concentradas, sobretudo, no governo federal por força da distribuição constitucional de competências na área educacional ${ }^{1}$.

A diversidade de modelos de autonomia no país revela que não há tratamento uniforme para a matéria, que a autonomia atribuída aos setores público e privado tem consequências diversas em cada um deles e que a proteção e a regulamentação da autonomia ainda são necessárias em face de persistentes limitaçóes. Também demonstra que as pressóes e interferências na autonomia variam, em graus equivalentes, do poder estatal para as regras de mercado. Esse artigo analisou todos esses aspectos. Iniciou-se pela gênese do art. 207 e seu sentido jurídico. A seguir, examinou-se os efeitos da autonomia universitária em relação às 
universidades públicas e privadas, destacando-se que sua eficácia resulta mais da regulamentação e da prática que do status constitucional e que implica, sobretudo, responsabilidade institucional. Não há, em seu conteúdo, nada de novo ou inovador em termos de demonstraçóes estatísticas ou interpretaçôes transdisciplinares. Trata-se, pelo contrário, de uma síntese de parte da bibliografia existente sobre o ensino superior, constatando-se que algumas de suas conclusóes se evidenciavam já no início dos anos 2000 .

\section{Autonomia universitária na Assembleia Constituinte: a gênese do art. 207}

As discussóes relativas ao ensino superior nas três etapas da Assembleia Constituinte - comissões e subcomissóes temáticas, comissão de sistematização e plenário (Emenda Constitucional no 26, de 27/11/1985) - giraram, sobretudo, em torno da destinaçâo de recursos públicos, como ocorreu em relação à educação em geral (PINHEIRO, 1996).

Debates principiológicos ou maior preocupação com os problemas inerentes à defasagem e à diversidade do sistema de ensino superior no país pouco ocorreram (BRASIL, 1987a). Prova disso foi a recorrência do financiamento das universidades federais - potencializada por períodos de greve nos anos de 1985 e 1987 (FERREIRA, 1986) —, deixando de lado o debate de aspectos inerentes à relação de complementaridade já estabelecida entre o setor público e o privado. O resultado, na redação final da Constituição, foram seis artigos (206; 207; 209; 208, V; 218, no capítulo da Ciência e Tecnologia; e 242, no Ato das Disposiçôes Constitucionais Gerais), dos quais apenas dois tocam o ensino superior diretamente, os arts. 207 e 208, V (posteriormente, pela Emenda Constitucional $n^{\circ} 85 / 2015$, foi acrescentado mais um parágrafo ao art. 213 , relativo ao apoio financeiro do poder público a universidades). No decorrer dos trabalhos, a autonomia universitária acabou por centralizar as emendas sobre o ensino superior. Nesse percurso, as propostas giraram em torno de sua limitação, tendo sido o seu exercício sucessivamente condicionado à lei ordinária, ao controle social e à exigência de indissociabilidade entre ensino e pesquisa, com larga vitória dessa última sobre os demais (NUNES, 2013).

Na Subcomissão de Educação, Cultura e Desporto, por exemplo, a tônica foi a inclusão da expressão "nos termos da lei" na redação do artigo, proposta que não vingou nas etapas seguintes. Anos mais tarde, a intenção de condicionar a autonomia à lei seria novamente expressa, no governo de Fernando Henrique, por via da Proposta de Emenda Constitucional no 233/95, enviada ao Congresso Nacional, mas sem seguimento, dada a reação negativa das universidades públicas, especialmente as do sistema paulista. 
Na primeira etapa de discussóes, portanto, o legislador constituinte não vislumbrava a autonomia universitária sem regulamentação; o objetivo era solucionar, ao menos em tese, os problemas de financiamento e controle na esfera pública. A autonomia universitária regulamentada (nos termos da lei), porém seria vencida pela autonomia tradicional (sem regulamentação), incorporada à redação final da Constituição e assim mantida até hoje, associada à concepção da universidade de pesquisa.

O segundo fato digno de nota foi uma espécie de reserva de mercado da autonomia, por assim dizer, em favor das universidades, à época já em número expressivamente inferior ao das instituiçóes isoladas (83 instituiçóes contra mais de 700 estabelecimentos não universitários). Nos anos 1970, o setor privado havia crescido por meio da criação de instituiçóes isoladas enquanto o setor público ampliara sua esfera de atuação investindo na qualidade da pesquisa, da pós-graduação e da extensão, impulsionado pela Reforma Universitária promovida pela Lei no 5.540 , de 1968.

Em Plenário, apenas as emendas voltadas à autonomia das universidades foram aprovadas, sem extensão às instituiçóes não universitárias. A não aprovação da Emenda Popular no 49, de responsabilidade da Confederação dos Professores do Brasil, da Associação Nacional dos Docentes e da União Nacional dos Estudantes (Emenda PE00049-1; Emenda 1P20702-9) ilustra essa situação (BRASIL, 1987b).

Somente em 1996, a Lei de Diretrizes e Bases da Educação Nacional (LDB), em seu art. $54, \$ 2^{\circ}$, ampliou as possibilidades de concessão de autonomia a outras instituiçóes de ensino superior, ocasião em que voltaria a crescer, no setor privado, após período de estagnação notado nos anos de 1980 (SAMPAIO, 2014b). A alteração deu-se não na forma antes vislumbrada pela Emenda 49, mas mediante avaliação do Poder Público, desde que comprovada alta qualificação para o ensino ou para a pesquisa, com possibilidade de suspensão temporária de prerrogativas de autonomia (art. $46, \$ 1^{\circ}$ ). O que significa dizer que, na LDB, a concessão de autonomia está vinculada à qualidade — e não ao modelo da indissociabilidade entre ensino e pesquisa (em consonância com o art. 45 da LDB, que reconhece que as instituiçóes de ensino superior apresentam diversos graus de abrangência e especialização, nova vertente da associação ou dissociação entre ensino e pesquisa).

Vencida a fase de votação dos substitutivos da Comissão de Sistematização nas primeiras votaçóes no Plenário foi alterado o tratamento conferido à autonomia universitária, que seria incluída entre os princípios do ensino nos artigos 211, X (BRASIL, 2018) e 206, VII (BRASIL, 1988a), respectivamente. O texto promulgado em 5 de outubro de 1988 no Diário Oficial da União, contudo, apresentou nova alteração na redação, proposta pelo então senador Fernando Henrique Cardoso (NUNES, 2013). Em apenas um artigo, o legislador 
constituinte fixou norma cogente, completa, indicando o conteúdo do direito e o respectivo sujeito.

\section{A autonomia universitária na Constituição Federal de 1988: o sentido jurídico do art. 207}

No art. 207, o sentido da autonomia universitária exprime o conceito geral de autonomia no direito público: poder derivado funcional, limitado pelo ordenamento que lhe deu causa (GIANNINI, 1959; BIELSA, 1938; MENDES DE ALMEIDA JR., 1912). Poder derivado, porque a autonomia só existe e se legitima em razáo do ordenamento que consente em sua existência; funcional, porque é um instrumento de natureza pública, destinado a operacionalizar o cometimento de tarefas públicas; limitado, porque não implica soberania ou independência.

A jurisprudência das Cortes Superiores é pacífica a esse respeito. No Supremo Tribunal Federal, por exemplo, restou assentado que: "Nos termos da jurisprudência deste Tribunal, o princípio da autonomia universitária não significa soberania das universidades, devendo estas se submeter às leis e demais atos normativos" (Recurso Extraordinário no. 561.398, Agravo Regimental. Relator Ministro Joaquim Barbosa, j. 23-6-2009, 2a T, DJE de 7-8-2009) (BRASIL, 1988).

Para o Direito, a autonomia é o efeito de uma limitação que a lei impóe a si mesma. Significa regular, com normas próprias, situaçóes intencionalmente não alcançadas pela lei, tendo em vista garantir e proteger certos interesses (ZANOBINI, 1950; SANTI ROMANO, 1964; BANDEIRA DE MELLO, 1968). O Estado, ao conceder autonomia a um ente, o faz por autolimitação. Por consequência, reconhece e adota, em seu sistema jurídico, o direito próprio produzido pelo ente autônomo, declarando-o tão obrigatório quanto suas próprias leis.

No Brasil, detêm autonomia político-administrativa a União, os Estados, Municípios e Distrito Federal, conforme dispóe o art. 18 da Constituição. Além das universidades, a Constituição ainda garante autonomia aos partidos políticos (art. 16, $\$ 1^{\circ}$ ), ao Poder Judiciário (art. 99), ao Ministério Público (art. 127, $\$ 2^{\circ}$ ), às Defensorias Públicas Estaduais (art. 134, $\$ 2^{\circ}$ ), aos órgãos e entidades da administração direta e indireta (art. $37, \$ 8^{\circ}$ ), às entidades desportivas e associaçóes (art. 217, I) e às instituiçôes de pesquisa científica e tecnológica (art. 207, $\$ 2^{\circ}$ ). A autonomia dos sistemas de ensino, em regime de colaboração recíproca (CF, arts. 211 e 214), é consequência da organização político-administrativa da Federação.

Todas essas instituiçóes criadas para desempenhar funções sociais específicas de interesse público têm constitucionalmente asseguradas diferen- 
tes esferas e graus de autonomia, até mesmo com possibilidade de ampliação mediante contrato (como os órgãos e entidades da administração direta e indireta). Em nenhum dos casos, preocupou-se o legislador constitucional em definir a autonomia ou remeter a sua definição à lei, o que significa dizer que o seu conteúdo e limites devem ser individualmente extraídos do próprio texto constitucional. Ainda que a lei elenque as prerrogativas da autonomia - como ocorre em relação à autonomia universitária na $\mathrm{LDB}$ —, o faz a título exemplificativo, não exaustivo.

No plano da legislação ordinária, a LDB prevê a liberdade de organização dos sistemas de ensino sob a coordenação da União (art. 80) e a concessão, pelos sistemas de ensino, de progressivos graus de autonomia pedagógica, administrativa e de gestão financeira para as unidades públicas de educação básica (art. 15), assim como às instituiçóes que comprovem alta qualificaçáo para o ensino ou para a pesquisa, mediante avaliação (art. $54, \$ 2^{\circ}$, c/c art. 46, $\$ 1^{\circ}$ ), como ocorre em relação aos centros universitários.

Destacam-se, nesse conjunto, as universidades públicas, por causa das possibilidades de fracionamento e flexibilização do regime jurídico da Administração Pública que derivam da autonomia que lhes foi assegurada pelo art. 207 da Constituição. Tal circunstancia lhes confere uma posição singular no corpo da Administração Indireta, confirmada pela LDB em seu art. 54:

As universidades mantidas pelo Poder Público gozarão, na forma da lei, de estatuto jurídico especial para atender às peculiaridades de sua estrutura, organizaçáo e financiamento pelo Poder Público, assim como dos seus planos de carreira e do regime jurídico do seu pessoal (BRASIL, 1996).

É o que também se confirma em face das disposições dos art. 53 e 54 da LDB, relativamente aos elencos exemplificativos das prerrogativas de autonomia das universidades. Para as universidades públicas, porém, o regime jurídico administrativo de direito público que lhe garante prerrogativas e privilégios (como a liberdade de selecionar e dispensar servidores, de fixar vencimentos, celebrar contratos etc.), é o mesmo que lhe impóe restriçóes, além de sujeitá-las a mecanismos formais de controle interno e externo.

Pode-se concluir, portanto, não ser raro nem excepcional a Constituição ou a lei ordinária atribuírem prerrogativas de autonormação a entes jurídicos, tendo em vista potencializar sua atuação. Entre esses, na área educacional, universidades, sistemas e instituições de ensino foram fortemente valorizados pelo legislador constitucional e pelo legislador ordinário para bem desempenharem suas funçóes.

O problema, portanto, está em tornar-se efetiva a norma do art. 207. Em outras palavras, como torná-la materialmente possível? 
A norma constitucional não tem existência fora da realidade (HESSE, 1991). Todos os direitos dependem de atuaçóes estatais, meios institucionais, condiçôes fáticas e jurídicas para se realizarem. Essas são as condiçôes que garantem a eficácia social da norma, a possibilidade de ela ser aplicada e observada.

\section{Trinta anos de garantia da autonomia universitária: um balanço da efetividade do art. 207}

Do ponto de vista jurídico, a constitucionalização da autonomia universitária conferiu maior segurança e estabilidade às atividades universitárias em relação à legislação anterior, posto que apenas mediante emenda constitucional poderá ser alterada a garantia. A norma do art. 207 é de aplicação imediata e eficácia plena; desde sua edição vinculou a ação do Judiciário e a dos poderes legislativos da União e dos Estados, bem como a atuação dos Conselhos de Educação. Qualquer determinação em contrário é inconstitucional (Ranieri, 2013). A esse movimento, somam-se a Lei no $9.394 / 96$ e a jurisprudência dos Tribunais.

Decorridos 30 anos desde 1988, os efeitos do art. 207 são contraditórios: no setor público, à exceção do sistema paulista, a autonomia não se efetivou; e os problemas recorrentes de financiamento e gestáo permanecem no sistema federal de ensino superior. No setor privado, a autonomia favoreceu a expansão do setor a partir da década de 1990, sem garantia de qualidade do ensino (GOMES \& MORAES, 2012; SAMPAIO, 2014b). Resultados indesejados pelo legislador constituinte e que reclamam compreensão e revisão das condiçóes que lhes deram causa.

O setor público de ensino superior compreende as instituiçóes mantidas pelo Poder Público federal, estadual e municipal (LDB, art. 19, I). A peculiaridade do sistema brasileiro fica por conta das instituiçóes municipais privadas, mantidas por mensalidades e não por recursos públicos (exceção ao art. 206, IV da CF, por força do art. 242 do Ato das Disposiçóes Constitucionais Gerais); tais instituiçóes, assim como todas as demais instituições privadas, integram o sistema federal de ensino. Cada sistema de ensino (federal, estadual, municipal) tem autonomia para regulamentar suas próprias instituições (CF, art. 18; LDB, arts. 9, 10 e 11).

Todas as instituiçóes de ensino superior, públicas e privadas estão submetidas à autorização e avaliação de qualidade pelo Poder Público, em diferentes graus, conforme disponham ou não de autonomia.

As instituiçóes públicas submetem-se às normas de direito administrativo e financeiro que ordenam a Administração Pública, sem exceçôes (como as normas orçamentárias e financeiras públicas, por exemplo) e estão sujeitas a controle 
contábil, financeiro e orçamentário dos Tribunais de Contas, além de restrições relativas ao uso dos recursos vinculado à educação previstas na LDB (art. 70). Também se submetem a mecanismos formais de controle interno e externo, inclusive no que diz respeito aos limites da Lei de Responsabilidade Fiscal (LRF), a Lei Complementar no 101, de 04/05/2000 (RANIERI, 2015). Como as universidades públicas integram a administração indireta e atuam mediante repasse de verbas públicas vinculadas à educação, na forma do art. 169 da CF, os princípios gerais de responsabilidade de gestão expressos no art. $1^{\circ}$ da LRF devem ser observados (princípio da legalidade, art. 37 da CF).

Estudos empíricos relativos à autonomia das universidades estaduais paulistas (LUQUE, 2015; AGOPYAN \& TONETO JR., 2015) demonstram que se as disputas anuais por recursos públicos são um dos embates inerentes e inevitáveis no modelo de financiamento do Decreto no 29.598/89, os resultados alcançados com a estabilidade de recursos ao longo dos anos possibilitaram melhor planejamento das atividades universitárias e melhores resultados acadêmicos. Demonstram, também, que o regime de autonomia de gestão financeira e patrimonial exige, sobretudo, responsabilidade institucional.

A pesquisa de Sassaki (2016), centrada nas causas e consequências do desequilíbrio financeiro ocorrido na Universidade de São Paulo, em razão da ampliação de gastos promovida no período de 2010 a 2013, revela o imperativo do aprimoramento da gestão pública e a promoção de accountability e publicidade no setor público. Em 2017, de acordo com princípios da LRF, a USP aprovou os chamados Parâmetros de Sustentabilidade Econômico-Financeira, que estabelecem limites de despesas totais com pessoal, que não devem ultrapassar o patamar de $85 \%$ das despesas correspondentes às liberaçóes mensais de recursos do Governo do Estado. Preveem, ainda, a elaboração de um planejamento plurianual e o planejamento de despesas que onerem exercícios orçamentários futuros e de investimentos que acarretem novas despesas de custeio, além da formação de uma reserva patrimonial de contingência. Essa reserva deverá ser formada por excedentes orçamentários em valor aproximado a 50\% dos orçamentos anuais, calculados como média dos últimos quatro anos (USP, 2017).

Em outras palavras, responsabilidade institucional e responsabilidade objetiva dos dirigentes são componentes da autonomia e requerem atençáo permanente, sob pena de não realização do Direito, ademais de incorrer em improbidade administrativa.

Contudo, são as universidades federais, em particular, que padecem com a não efetividade do art. 207, posto que a legislação ordinária não controlou as principais variáveis que interferem na eficácia de sua atuação autônoma: condiçóes de financiamento e especialidade do seu regime jurídico (RANIERI, 2000), ainda que desfrutem, em larga medida, de autonomia didático-cientifica, com liberdade de ensino e pesquisa. 
Comparativamente, a autonomia das universidades privadas apresenta margens mais amplas de administração e de gestão autônomas, expressas pela autonomia da vontade e liberdade de contratação, além de não operarem com recursos públicos. Além disso, náo se encontra obrigada a proceder nos termos do inciso V, do art. 206 da Constituição, que exige gestão democrática do ensino público.

$\mathrm{Na}$ doutrina contemporânea sobre o ensino superior, Schwartzman (2014) e Sampaio (2014a) enfatizam o impacto do art. 207 na expansão do setor privado a partir da década de 1990. De fato, se em 1996, ano da edição da LDB, o conjunto de universidades incorporava, no total, 136 instituiçóes, sendo 64 privadas (BRASIL, 1998), em dez anos, o número dessas últimas triplicou (BRASIL, 2003). Estimuladas pela possibilidade de remanejar vagas, criar e extinguir cursos (CF, art. 207, c/c art. 53 da LDB), instituiçóes isoladas procederam fusóes, incorporaçóes e desconcentraçóes regionais, movimentos que explicam, em larga medida, o deslocamento do ensino superior em direção ao mercado.

Os efeitos do Decreto no 2.306/1997² e de suas alteraçóes foram cruciais nesse movimento (MARTINS, 2009; SAMPAIO, 2014a). Se a possibilidade das mantenedoras de instituições de ensino superior, previstas no inciso II, do art. 19, da LDB, assumirem natureza comercial as alijava do repasse de recursos públicos (CF, art. 213, I) e as excluía da imunidade fiscal (CF, art. 150, VI, c), também potencializava a expansão do ensino privado.

Sem entrar na análise jurídica do revogado Decreto, já realizada anteriormente (RANIERI, 2000), as consequências imediatas do Decreto - a submissão do regime da legislação mercantil pelas mantenedoras das instituiçóes privadas, de finalidade lucrativa, quantos aos encargos fiscais, parafiscais e trabalhistas; e a transformação das próprias instituiçōes em mercadorias - pavimentaram o caminho das grandes fusōes de grupos educacionais privados do início do século XXI.

Indireta e adicionalmente, o Decreto no 2.306 repercutiu de forma negativa nas entidades sem fins lucrativos (instituiçóes de ensino confessionais, comunitárias e filantrópicas). Por causa das mudanças na legislação previdenciária, foram consideradas como de assistência social, para fins de isenção da contribuição para a seguridade social, as entidades que prestem gratuitamente e em caráter exclusivo, benefícios e serviços a quem necessitar (Lei no 9.732, de 11/12/98). A medida desestimulou a atividade educacional não lucrativa, demonstrando claro descompasso entre meios e fins, no qual se contrapóe o valor "distribuição de bens" à "utilização de recursos escassos" (RANIERI, 2000). O exemplo ilustra que políticas setoriais, no âmbito da administração direta, podem não provocar um efeito articulado às açốes estatais. 
Para que bem se compreenda o regime jurídico das instituiçóes privadas de ensino superior, breves notas sobre a distinção entre instituição mantenedora e instituição mantida se fazem necessárias. $\mathrm{O}$ art. 19 da LDB determina a natureza privada das instituições de ensino em função das pessoas físicas ou jurídicas de direito privado que as mantêm e administram. A formulaçáo se repete no art. 20, quando da discriminação das categorias a que devem, necessariamente, se enquadrar (comunitária, confessional, filantrópica, ou nenhuma destas). A diferenciação, nessas hipóteses, diz respeito às condições e requisitos impostos às pessoas físicas ou jurídicas que as mantêm e não às instituições propriamente ditas.

Revela-se, assim, a preocupação da LDB com a atividade econômica na área educacional exercida, via de regra, por dois entes distintos: uma pessoa física ou jurídica, com capacidade econômico-financeira, titular do patrimônio (a mantenedora), e outra pessoa jurídica, prestadora das atividades educacionais, que congrega a capacidade física instalada e os recursos humanos disponíveis (a mantida). Em decisão exarada na Ação Direta de Inconstitucionalidade no 2501-5, o Supremo Tribunal Federal confirmou tal entendimento (BRASIL, 2001). A possibilidade de cisão das atividades de ensino, propriamente ditas, das de administração institucional, não é nova - está presente na legislação educacional brasileira desde a Lei no 4.024/61 (art. 21).

Consequência subjacente da maior liberdade e das regras de mercado que a influenciam foi a transformação da autonomia universitária em autonomia da mantenedora, ente que efetivamente decide sobre oferta de cursos, expansão de vagas, cargos, carreira etc. (DURHAM, 2005; MORETTI, 2013), também em evidente descompasso com a intenção do legislador constituinte.

Feita essa digressão temos, no sistema brasileiro, no conjunto das instituiçóes privadas de ensino superior, $40 \%$ de empresas com finalidade lucrativa, o que implica não apenas cobrança de mensalidade e distribuição de lucros, mas: o fenômeno das fusôes e aquisiçôes de outras empresas educacionais (consolidação), a abertura de capital na bolsa de valores e a parceria com redes internacionais de educação (SAMPAIO, 2014b). Em 2014, oito grupos educacionais privados concentravam uma em cada quatro matrículas no país (FUNDAÇÃO GETULIO VARGAS, 2014).

Outro aspecto que distingue a autonomia das universidades privadas das públicas é a profissionalização da gestão. Enquanto nas últimas são os membros do corpo docente que, tradicionalmente, se ocupam das atividades de planejamento e execuçáo econômico-financeira, nas primeiras a gestáo empresarial se consolida em grande parte das instituiçôes (SAMPAIO, 2014b).

Em suma, se não há, nem poderia haver, tratamento uniforme para a matéria em razão da heterogeneidade e dos diferentes regimes jurídicos das insti- 
tuiçóes. Parece evidente que a discrepância entre os setores deveria ser compensada de alguma forma, posto que incide em mais desigualdades no campo do ensino superior. A regulamentação da autonomia faz-se, portanto, necessária não só em face de persistentes limitações, mas também diante de distorções que a lógica da avalição permanente não eliminou.

\section{Qual futuro para a autonomia universitária?}

Desde o fim do século XX, a globalização, a cooperação internacional, o intercâmbio acadêmico, os blocos regionais, a inclusão da educação superior nas negociaçóes do Acordo Geral sobre Comércio de Serviços (GATS), sob a égide da Organização Mundial de Comércio, ampliaram o escopo e as finalidades do ensino superior. As universidades se projetam fora das fronteiras nacionais e são afetadas pela internacionalização da educação superior, processo traduzido na integração global do ensino, pesquisa e extensão universitárias, como decorrência da própria complexidade que se apresenta à instituição (BRUNNER, 2009), com impactos na autonomia universitária.

No âmbito nacional, não menos complexas se apresentam as relaçóes que as universidades mantêm com a sociedades contemporâneas, nas quais desenvolvimento econômico, produção de conhecimentos técnicos e científicos e crescentes exigências socioeconômicas e de igualdade de oportunidade integram as demandas acadêmicas.

Não por outras razóes, fala-se de "nova autonomia" (CLARK, 1998) ou em "autonomia reinventada" (CLARK, 2001), expressóes cunhadas para designar uma atitude mais ativa em comparaçáo à autonomia tradicional, associada a uma atitude passiva, à sombra do ente mantenedor, adequada à baixa complexidade das atividades universitárias do passado e aos limites locais e nacionais da atividade universitária. A autonomia reinventada de Clark (2001) supóe gestão especializada, financiamento diversificado, cultura empreendedora, visão de futuro e, sobretudo, a postura da não dependência de parte das instituiçóes.

Em um sistema universitário caracterizado pela diversidade de instituiçôes e pela heterogeneidade quanto à qualidade acadêmica, a forte presença do Estado não tem sido eficaz para garantir o controle das atividades ou a efetiva autonomia das instituiçóes. Assim, têm-se forjado as relaçóes entre Estado e as universidades no Brasil nos últimos 30 anos, sem maiores avanços em temáticas fundamentais como diversificação de modelos de financiamento, desenvolvimento de novos modelos de governança, gestão profissionalizada, fortalecimento dos sistemas de inovação e competitividade, excelência na pesquisa, internacionalização do ensino superior, relaçóes entre universidades e empresas, relaçóes entre universidade e sociedade, especificidade do regime das universidades públicas. 
$\mathrm{O}$ art. 207 vem apresentando mais resultados contraditórios que desempenho adequado de sua função social, a despeito do bem-sucedido modelo paulista. Aprimorar a autonomia universitária, tanto por parte do Poder Público quanto das próprias universidades, é condição vital para que não se transforme em mitologia jurídica, por falta de efetividade.

\section{Notas}

1. A União tem atuação educacional supletiva e redistributiva de âmbito nacional, inclusive em relação ao ensino superior (CF, art. 211). Reserva-se à União competência privativa para legislar sobre diretrizes e bases da educação nacional (CF, art. 22, XXIV); e competência concorrente à dos Estados e Distrito Federal para legislar sobre educação mediante normas gerais (CF, art. 24, IX).

2. Revogado pelo Decreto no 3.860/2001, que foi revogado pelo Decreto no 5.773/2006, este último revogado pelo Decreto no. 9.235/2017.

\section{Referências}

AGOPYAN, V.; TONETO, R.J. O desequilíbrio financeiro da Universidade de São Paulo: origens e medidas de ajuste. Universidade em Movimento, São Paulo, n. 105, p. 19-32, abr./jun. 2015. https://doi.org/10.11606/issn.2316-9036.v0i105p19-32

BANDEIRA DE MELLO, C.a. 1968. Natureza e Regill/e Jurídico das Autarquias. São Paulo, Revista dos Tribunais

BIELSA, R. Derecho Administrativo. 3. Ed. Buenos Aires: Libreria J. Lajoane y Cia., 1938. tomo II.

BRASIL. Assembleia Nacional Constituinte. Emendas ao anteprojeto do relator da subcomissão. Brasil, 1987a. Disponível em: <http://www.camara.gov.br/internet/ constituicao20anos/DocumentosAvulsos/vol-208.pdf>. Acesso em: 5 maio 2018.

- Assembleia Nacional Constituinte. Comissão de Redação. Projeto de Constituição C. Brasil, 1988a. Disponível em: <http://www.camara.gov.br/internet/ constituicao20anos/DocumentosAvulsos/vol-314.pdf>. Acesso em: 6 maio 2018.

- Assembleia Nacional Constituinte. Emendas Populares. Brasil, 1987b.

v. 231. Disponível em: <http://www.camara.gov.br/internet/constituicao20anos/ DocumentosAvulsos/vol-231.pdf >. Acesso em: 5 maio 2018.

Constituição da República Federativa do Brasil de 1988. Brasil, 1988b. Disponível em: <http://www.planalto.gov.br/ccivil 03/constituicao/constituicao.htm>. Acesso em: 15 maio 2018.

. Decreto no 29.598, de 2 de fevereiro de 1989. Dispóe sobre providências visando a autonomia Universitária. Diário Oficial do Executivo, p. 1, 3 fev. 1989. Disponível em: <https://www.al.sp.gov.br/norma/?id=35148>. Acesso em: 15 maio 2018. 
. Lei no 9.394, de 20 de dezembro de 1996. Brasil, 1996. Disponível em: < $\underline{\text { http:// }}$ www.planalto.gov.br/ccivil_03/LEIS/L9394.htm>. Acesso em: 15 maio. 2018.

. Ministério da Educação. Evolução do Ensino Superior no Brasil, 1980-1996. Brasília: Instituto Nacional de Estudos e Pesquisas Educacionais Anísio Teixeira (INEP), 1998.

- Ministério da Educação. Instituto Nacional de Estudos e Pesquisas Educacionais Anísio Teixeira. Diretoria de Estatísticas e Avaliação da Educação Superior. Censo da educação superior. Brasil, 2003. Disponível em: <http://download.inep.gov.br/download/ superior/censo/2004/resumo_tecnico_050105.pdf>. Acesso em: 11 maio 2018.

Projeto de Constituição. Redação para o segundo turno de discussão e votação constituinte Bernardo Cabral. Documentos Avulsos. v. 299. Disponível em: <http://www. camara.gov.br/internet/constituicao20anos/DocumentosAvulsos/vol-299-sup01.pdf>. Acesso em: 6 maio 2018.

Sinopse Estatística da Educação Superior de 2016. Brasília: Instituto Nacional de Estudos e Pesquisas Educacionais Anísio Teixeira (INEP), 2017.

Supremo Tribunal Federal. Ação Direta de Inconstitucionalidade (Med. Liminar) - 2501. Brasil, 2001. Disponível em: $<$ http://www.stf.jus.br/portal/peticaoInicial/ verPeticaoInicial.asp?base $=$ ADIN\&s $1=$ estado $\% 20$ minas $\% 20$ gerais $\&$ processo $=2501>$. Acesso em: 15 maio. 2018.

Brunner, J.J.; Uribe, D. Mercados Universitarios: El Nuevo Escenario de la Educación Superior. Santiago, Ediciones Universidad Diego Portales, 2007. Disponível em: $<\underline{\text { http:// }}$ biblioteca.usbbog.edu.co:8080/Biblioteca/BDigital/44129.pdf>. Acesso em: 22 maio 2018.

CLARK, B.R. Creating Entrepreneurial Universities: Organizational Pathways of Transformation. Issues in Higher Education. Oxford: Pergamon Press, 1998.

The Entrepreneurial University: new foundations for collegiality, autonomy and achievement. Higher Education Management, v. 13, n. 2, 2001. Disponível em: <http:// www.oecd.org/education/imhe/37446098.pdf>. Acesso em: 5 maio 2018.

DURHAM, E.R. A autonomia universitária: extensão e limites. Núcleo de Pesquisas sobre o Ensino Superior (NUPES). Documento de Trabalho 03/05. São Paulo: Universidade de São Paulo, 2005. Disponível em: <https://ufam.edu.br/attachments/article/2317/ Artigo\%20Autonomia\%20Universit\%C3\%A1ria\%20Eunice\%20Durham.pdf>. Acesso em: 5 maio 2018.

FERREIRA, P. Educação e Constituinte. Revista de Informação Legislativa, v. 23, n. 92, p. 171-94, out./dez. 1986. Disponível em: <http://www2.senado.leg.br/bdsf/handle/ id/181734 >. Acesso em: 15 maio. 2018.

FUNDAÇÃO GETÚLIO VARGAS. Escola de Direito de São Paulo. Núcleo de Metodologia do Ensino. Observatório do Ensino do Direito. v. 2, n. 1, nov. 2014. Disponível em: $<\underline{\text { http:// }}$ direitosp.fgv.br/observatorio-ensino-direito >. Acesso em: 14 maio 2018.

GIANNINI, M.S. Autonomia - Teoria Generale e Diritto Pubblico. In: ENCICLOPÉDIA DEL DIRITTO. Milano: Giuffré, 1959. v. IV. 
GOMES, A.M.; MORAES, K.N. de. Educação superior no Brasil contemporâneo: transição para um sistema de massa. Educação \& Sociedade, Campinas, v. 33, n. 118, p. 171-190, mar. 2012. Disponível em: <http://www.scielo.br/scielo.php?script=sci arttext\&pid=S0101-73302012000100011\&lng=en\&nrm=iso $>$. Acesso em: 15 maio 2018. http://dx.doi.org/10.1590/S0101-73302012000100011

HESSE, K. A força normativa da Constituição. Tradução de Gilmar Ferreira Mendes. Porto Alegre: Sergio Antonio Fabris, 1991.

LUQUE, C.A. Alguns desafios para o financiamento das universidades públicas estaduais do Estado de São Paulo. Universidade em Movimento, São Paulo, n. 105, p. 9-18, abr./ jun. 2015. https://doi.org/10.11606/issn.2316-9036.v0i105p9-18

MARTINS, C.B. A reforma universitária de 1968 e a abertura para o ensino superior privado no Brasil. Educação \& Sociedade, Campinas, v. 30, n. 106, p. 15-35, jan./abr. 2009. Disponível em: <http://dx.doi.org/10.1590/S0101-73302009000100002>. Acesso em: 14 maio 2018.

MENDES DE ALMEIDA JR., J. A idéia de autonomia e a pretendida transição do ensino oficial. São Paulo: Typ. Siqueira Nagel e Co., 1912.

MORETTI, D.M. A compatibilidade entre a lógica econômica e o ensino superior, após a Constituição Federal de 1988: o caso da Anhanguera Educacional Participaçóes S.A. Dissertação (Mestrado em Direito do Estado) - Universidade de São Paulo, São Paulo, 2013. Disponível em: <http://www.teses.usp.br/teses/disponiveis/2/2140/tde-01092016150021/fr.php>. Acesso em: 15 maio. 2018.

NUNES, E. de O. Educação Superior no Brasil: estudos, debates, controvérsias. Rio de Janeiro: Garamond, 2013.

PINHEIRO, M.F. O público e o privado na Educação: um conflito fora de moda? In: FÁVERO, O. (Org.). A Educação nas Constituintes Brasileiras: 1823-1988. Campinas: Autores Associados, 1996. p. 255-291.

RANIERI, N. Autonomia Universitária: as universidades públicas e a Constituição Federal de 1988. 2. ed. São Paulo: Imprensa Oficial do Estado de São Paulo, 2013.

Autonomia Universitária e Lei de Responsabilidade Fiscal: relaçôes e implicaçóes. Universidade em Movimento, São Paulo, n. 105, p. 33-42, abr./jun. 2015. https://doi. org/10.11606/issn.2316-9036.v0i105p33-42

Educação Superior, Direito e Estado: Na Lei de Diretrizes e Bases (Lei no 9.394/96). São Paulo: Edusp/FAPESP, 2000.

ROMANO, S. 1964. Fragmelltos de UII DiccionarioJurídico. Buenos Aires, Europa -América.

SAMPAIO, H. Novas dinâmicas do ensino superior no Brasil: o público e o privado. In: SCHWARTZMAN, S. (Org.). A educação superior na América Latina e os desafios do século XXI. Campinas. Editora da Unicamp, 2014a. p. 139-192.

. Setor privado de ensino superior no Brasil: crescimento, mercado e Estado entre dois séculos. In: OLIVEIRA, M.L.B. de (Org.). O ensino superior no Brasil: credencial, méritos e coronéis. Rio de Janeiro: 7 Letras, 2014b. p. 103-126. 
SASSAKI, A.H. Governança e conformidade na gestão universitária. Tese (Doutorado em Administração), Universidade de São Paulo, São Paulo, 2016. Disponível em: <http:// www.teses.usp.br/teses/disponiveis/12/12139/tde-21102016-134240/pt-br.php>. Acesso em: 15 maio. 2018.

SCHWARTZMAN, S. (Org.) A educação superior e os desafios do século XXI: Uma introdução. In: SCHWARTZMAN, S. A educação superior na América Latina e os desafios do século XXI. Campinas: Editora da Unicamp, 2014. p. 15-46. UNIVERSIDADE DE SÃO PAULO (USP). Resolução no 7.344, de 30 de maio de 2017. São Paulo, 2017. Disponível em: <http://www.leginf.usp.br/?resolucao=resolucao-no-7344-de-30-demaio-2017>. Acesso em: 15 maio. 2018.

ZANOBINI, G.1950. Autonomia Pubblica e Privata. In: Scriui Giuridici in ollore di Frallcesco Carnelutti. Pádua, Casa Editrice Dot!. Antonio Milani, pp.183-189.

Recebido em 25 de junho de 2018.

Aceito em 18 de agosto de 2018. 